\title{
Diätetik aus dem Orient
}

\section{Iris Ritzmann}

Prof. Dr. med. et lic. phil., Mitglied der Redaktion Medizingeschichte

Der Begriff der Diätetik umfasst viel mehr als eine Diät. Diätetik bezieht laut antikem Gesundheitsregiment jene körperlichen Zustände mit ein, die willentlich beeinflussbar sind. Zu diesen sechs «Res non naturales», den nicht von der Natur vorgegebenen Dingen, gehören Schlaf und Wachsein, Bewegung und Ruhe, Ernährung und emotionale Verfassung. Haupttenor dieser Gesundheitsregimenter ist, das richtige Mass zu finden.

Eines der bedeutendsten diätetischen Ratgeberbücher des arabischen Hochmittelalters ist das Werk Schachtafelen der Gesuntheyt oder - in der ursprünglich arabischen Sprache - Taqwim es-sihha, was Gesundheitstabellen bedeutet. Effektiv zielt der Titel nicht nur auf den Inhalt, sondern auch auf die aussergewöhnliche Form der Seitengestaltung ab: Es ist das erste Werk, das medizinische Inhalte in Tabellenform darstellt. Während rechts Kommentare stehen, nennt der Tabellen-

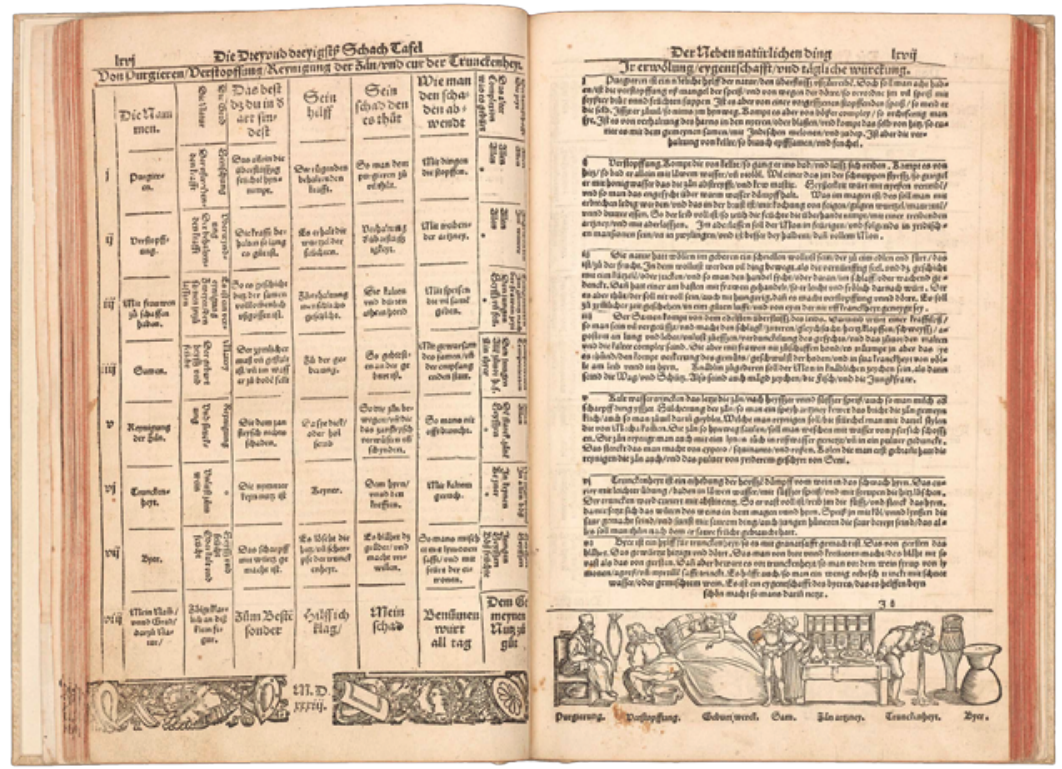

Ibn Butlan: Schachtafelen der Gesuntheyt, erste deutsche Übersetzung durch Stadtarzt Michael Herr, verlegt von Hans Schott in Strasbourg 1533, Sammlung Dr. Franz Käppeli. kopf auf der linken Seite den behandelten Gegenstand und charakterisiert ihn nach Vorkommen, Wirkungen und Anwendung. Damit lassen sich die Beschreibungen sehr rasch erfassen und völlig verschiedene Mittel untereinander vergleichen.

Die hier abgebildete erste deutsche Druckfassung von 1533 fügt am Textende eine Bildleiste an. Die Illustrationen stammen vom bekannten Holzschneider Hans Weiditz. Sie erlauben Rückschlüsse auf die Alltagskultur zur Zeit des Drucks. Die Ausführungen zur Darmtätigkeit etwa sind mit zwei unterschiedlichen Klosetts illustriert, einem stattlichen Nachtstuhl und einem kleineren, tragbaren Nachttopf, getrennt durch ein überdimensionales Klistier. Es folgt ein breites Bett, worin sich zwei Liebende vergnügen. Beischlaf wird hier mit "Geburtswerck» übersetzt, das gemäss Ibn Butlan erleichtert und fröhlich macht. Neben dem Bild eines Betrunkenen, der sich übergeben muss, prangt als letztes Sujet ein Fass Bier. Diese Reihung folgt einer Logik, allerdings nicht der heutigen: Bier wird als probates Mittel gegen Trunkenheit empfohlen.

Der Autor, der Arzt und nestorianische Christ Ibn Butlan (gest. 1064), kam im frühen 11. Jahrhundert in Bagdad zur Welt. Seine Schachtafelen schrieb er vermutlich gegen Ende seines Lebens in Antiochien. Zahlreiche arabische und lateinische Abschriften und Übersetzungen zeugen von der Beliebtheit dieses Werks. 1531 erschien der erste Druck auf Latein unter dem Titel Tacuinum sanitatis. Die mehrheitlich sinnesfreudige Lebenshaltung, die sich in den Schachtafelen spiegelt, widersprach freilich den moralischen Vorstellungen des 16. Jahrhunderts. Und so erstaunt es wenig, dass am Schluss des schönen Bandes ein grossformatiger Holzschnitt die Sünden und ihre Bestrafung in Erinnerung ruft.

Bildnachweis

Museum für medizinhistorische Bücher Muri (mmbm.ch) 